\title{
Prolonged Cardiac Arrest in Severe Bupropion Intoxication: Everything You Should Know About Anti-Arrhytmics, Transesophageal Echocardiography Guided Resuscitation and Extracorporeal Membrane Oxygenation
}

\author{
Caitlin Celis, MBBS; Melvin Willems, MD; Ben Pellens, MD; Stefanie Vandervelden, MD* \\ Department of Emergency Medicine, University Hospitals Leuven, Herestraat 49, 3000 Leuven, Belgium

\section{"Corresponding author} \\ Stefanie Vandervelden, MD \\ Consultant in Emergency Medicine, Department of Emergency Medicine, University Hospitals Leuven, Herestraat 49, 3000 Leuven, Belgium; \\ E-mail: stefanie.vandervelden@uzleuven.be
}

\section{Article information}

Received: December 9 ${ }^{\text {th }}, 2020$; Revised: January $4^{\text {th }}$, 2021; Accepted: January $4^{\text {th }}, 2021$; Published: January $6^{\text {th }}, 2021$

\section{Cite this article}

Celis C,Willems M, Pellens B,Vandervelden S. Prolonged cardiac arrest in severe bupropion intoxication: Everything you should know about anti-arrhytmics, transesophageal echocardiography guided resuscitation and extracorporeal membrane oxygenation. Emerg Med Open J. 202I; 7(I): I-6. doi: I0.17140/EMOJ-7-I58

\section{| ABSTRACT |}

A 30-year-old woman was admitted to the emergency department one and half hours after severe bupropion extended-release intoxication, estimated to be between 18 and $36 \mathrm{~g}$. She initially presented with seizures and later developed signs of cardiotoxicity with persisting sustained ventricular tachycardia. Despite multiple defibrillation attempts and the administration of sodium bicarbonate, calcium gluconate and magnesium, restoration of sinus rhythm was found unsuccessful. In another attempt to treat this refractory ventricular tachycardia lidocaine was given followed by deterioration to asystole. During cardiopulmonary resuscitation (CPR), the quality of chest compression was assessed and optimised using transoesophageal echocardiography. Eventually venoarterial extracorporeal membrane oxygenation (VA-ECMO) was needed to achieve hemodynamic stability. In this case report we discuss the successful use of VA-ECMO after bupropion intoxication, which has only been reported in 3 other cases but should be considered as one of the treatment options in severe overdose cases. Also, the rare complication of asystole after lidocaine administration and the value of transoesophageal echocardiography during CPR will be discussed.

\section{Keywords}

Bupropion; Intoxication; Extracorporeal membrane oxygenation; TEE guided resuscitation; Antiarrhythmic therapy.

\section{INTRODUCTION}

$\mathrm{B}$ upropion is a commonly prescribed antidepressant used for treating major depressive disorder, seasonal affective disorder as well as for anxiety, bipolar disorder and as an aid for smoking cessation. Bupropion is classified as an atypical monocyclic antidepressant with a chemical structure similar to amphetamine. ${ }^{1}$ It is a selective reuptake inhibitor of dopamine and norepinephrine.

Bupropion is available in an immediate release, a sustained release and an extended release form. The extended release form is known to have a peak plasma concentration at 5-hours. However, if an overdose is taken, the peak plasma concentration time can be prolonged. ${ }^{2}$ Most reported severe adverse effects of a bupropion intoxication are seizures and late onset cardiotoxicity with widening of the $\mathrm{Q}$ wave, $\mathrm{R}$ wave and $\mathrm{S}$ wave $(\mathrm{QRS})$-complex and prolongation of the Q-T corrected (QTc) interval. ${ }^{1-4}$

In this case report we discuss a patient that was seen in the Emergency Department (ED) after a severe bupropion extended release intoxication with the need for veno-arterial extracorporeal membrane oxygenation (VA-ECMO) to achieve hemodynamic stability. In the past, many cases of bupropion intoxication have been described. However, only 3 other cases were found describing the need for VA-ECMO after a severe bupropion overdose. ${ }^{5,6}$ During advanced life support (ALS), the patient experienced refractory sustained ventricular tachycardia (VT). Despite multiple defibrillation attempts and the administration of sodium 
bicarbonate, calcium gluconate and magnesium, restoration of sinus rhythm was found unsuccessful. In another attempt to treat this refractory VT lidocaine was given followed by deterioration to asystole. Lidocaine is a frequently used antiarrhythmic drug with the possible complication of asystole immediately after administration. However, it has only been reported a few times. ${ }^{7,8}$ To optimize the chest compressions during ALS, transoesophageal echocardiography was used to indicate the best placement of the Lucas ${ }^{\circledR}$ chest compression system.

\section{CASE REPORT}

A 30-year-old woman was admitted to the ED after ambulance intervention following an autointoxication of bupropion. The patient declared to have ingested 120 tablets. A number of 5 empty packages of both $150 \mathrm{mg}$ and $300 \mathrm{mg}$ extended release tablets were found, estimated to be a total dose between 18 and $36 \mathrm{~g}$. The patient had no relevant somatic or surgical history but had a psychiatric history with previous suicide attempts. Upon arrival on the scene, about 60-minutes after estimated drug ingestion, the patient was agitated and uncooperative. About 10 -minutes after arrival on the scene, she developed generalized tonic-clonic seizures lasting about 2-minutes for which diazepam was administrated intravenously. The patient's vital signs during transportation were oxygen saturation of $100 \%$ with $15 \mathrm{~L}$ of oxygen, a sinus tachycardia of 140 beats/minute, normotension, a temperature of $36.5^{\circ}$ Celsius and a fluctuating Glasgow Coma Scale between $3 / 15$ and 10/15. An additional dose of diazepam and lorazepam were given before arrival at the hospital. There were no signs of hyperreflexia or rigidity and pupils were bilaterally mydriatic, symmetric and reactive.

To secure the airway, tracheal intubation was performed in hospital after induction with propofol and rocuronium. Initial management focused on the continuation of mechanical ventilation and sedation to prevent recurrence of seizures together with monitoring of possible electrocardiogram (ECG) changes. Fifty (50) grams of activated charcoal was administrated via nasogastric tube and repeated every 4-hours. Aspiration through the nasogastric tube was performed however it was found unsuccessful.

Initial ECG showed a regular sinus rhythm of 125 beat/ minute, a narrow QRS-complex of 88 milliseconds and a QTc time of $435 \mathrm{~ms}$. There were no signs of ischemia present (Figure 1). The first arterial blood gas was obtained 45-minutes after admission at the $\mathrm{ED}$ and showed a $\mathrm{pH}$ of $7.35, \mathrm{pO}_{2} 108 \mathrm{mmHg}, \mathrm{pCO}_{2}$ $43.6 \mathrm{mmHg}, \mathrm{HCO}_{3} 24.3 \mathrm{mmol} / \mathrm{L}$, lactate $2.3 \mathrm{mmol} / \mathrm{L}$. Further laboratory investigations showed a glucose of $72 \mathrm{mg} / \mathrm{dL}, \mathrm{Na}^{+} 140$ $\mathrm{mmol} / \mathrm{L}, \mathrm{K}^{+} 3.29 \mathrm{mmol} / \mathrm{L}, \mathrm{HCO}_{3} 16.4 \mathrm{mmol} / \mathrm{L}, \mathrm{Cl}^{-1} 102 \mathrm{mmol} / \mathrm{L}$. Inflammatory markers, liver function tests, complete blood count and renal panel were all within normal ranges.

She soon developed a hypotension of $70 / 40 \mathrm{mmHg}$, for which noradrenalin was associated together with a $500 \mathrm{cc}$ bolus of crystalloids. ECGs were systematically taken every 2-hours. Over the next 8-hours the patient developed a bradycardia as low as $47 \mathrm{bpm}$ with widening of the QRS-complex up until 185 $\mathrm{ms}$ and prolongation of the QTc interval up to $519 \mathrm{~ms}$ (Figures 2-3). Since this rhythm was secondary to the bupropion induced sodium channel blockage, sodium bicarbonate was administrated twice (200 meq in total). A terlipressin drip was associated together with $1 \mathrm{~g}$ of calcium gluconate and 3 grams of magnesium. After 30-minutes the patient developed a torsades de pointes (TdP) for which an additional 100 meq of sodium bicarbonate (guided by the QRS-duration), magnesium and calcium chloride were given. Multiple synchronized defibrillations were administrated. Defibrillation consistently restored sinus rhythm for limited duration with persistent recurrence of initially TdP and VT later on. During sinus rhythm, atropine was associated to improve atrioventricular conduction. Due to the recurrent nature of the VT, an anti-arrhythmic drug was administered. It was decided to avoid amiodarone due to its QTc prolonging effect. A lidocaine bolus of $100 \mathrm{mg}$ was administered 12-minutes after the start of advanced life support (ALS) after which the patient developed asystole. Cardiopulmonary resuscitation (CPR) was assisted by the Lucas ${ }^{\circledR}$ chest compression system. To assure best possible placement, a transoesophageal echocardiography (TEE) was associated after 20-minutes. Based on the mid oesophageal long axis view

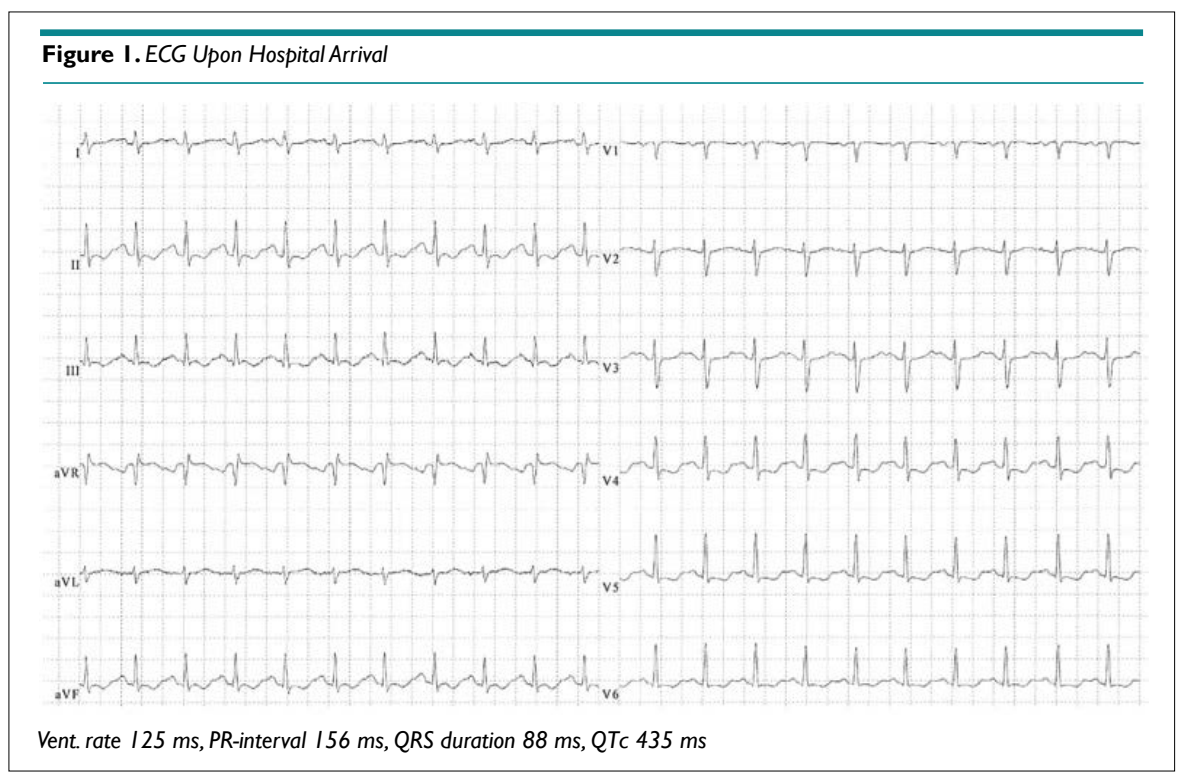



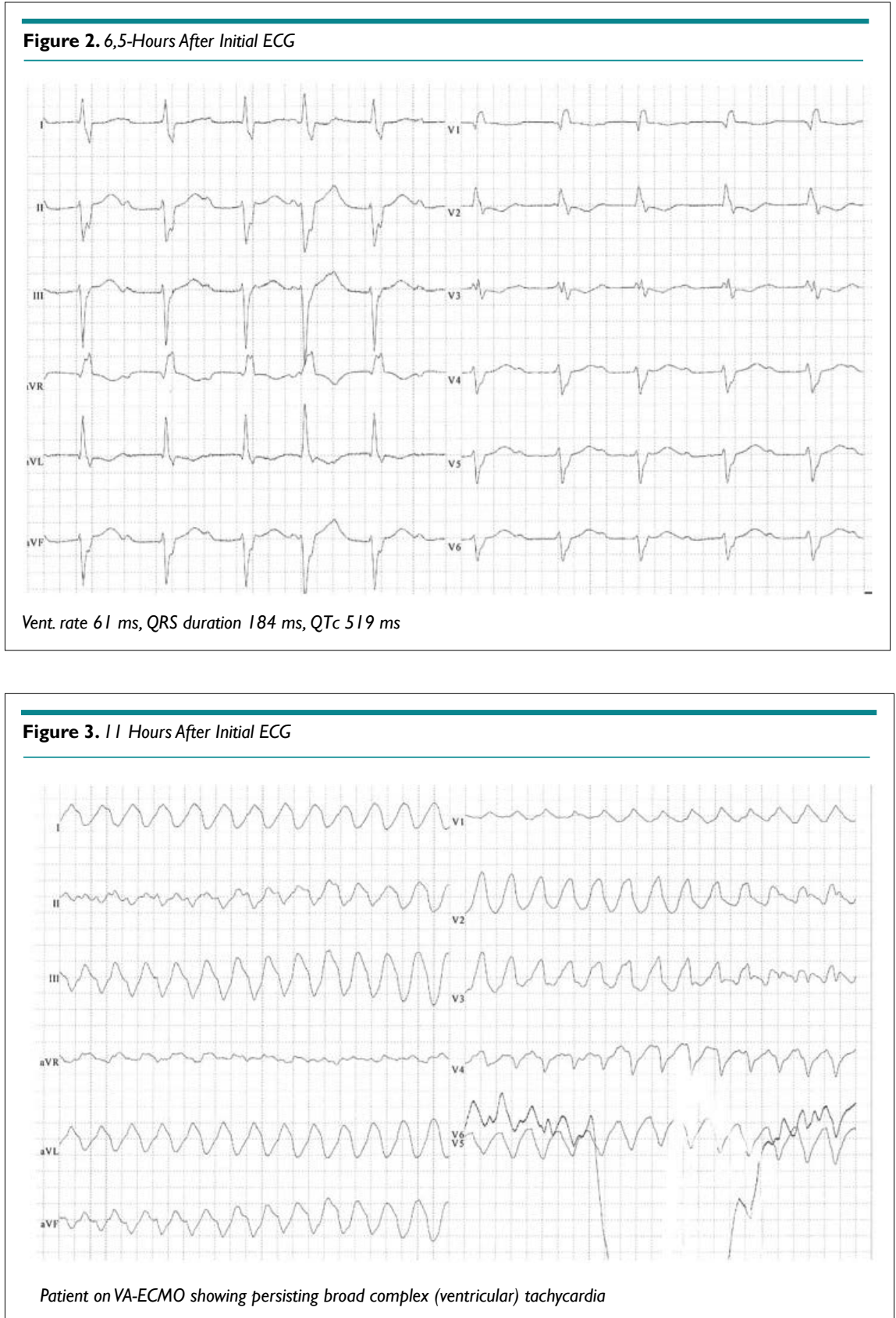

(MELAX), compressions were mainly on the outflow track with limited opening of the aortic valve, hence the position of the chest compression system was adjusted under TEE guidance. Given the refractory cardiac arrest setting, the decision to place VAECMO was taken, which was operational after 63-minutes of ALS. The patient was transferred to the intensive care unit where she remained in a refractory VT state for over an hour. Eventually the patient could be weaned from VA-ECMO over the next 48-hours. Four-days after hospital admission the patient could be extubated.

The patient had a full neurological and cardiac recovery and could be discharged from the intensive care unit after 6-days.

\section{DISCUSSION}

Bupropion is classified as an atypical monocyclic antidepressant with a chemical structure similar to amphetamine. ${ }^{1}$ It is a selective reuptake inhibitor of dopamine and norepinephrine. The optimal daily starting dosage has been described as $150 \mathrm{mg}$ per day. Maximum dose recommended per day is $450 \mathrm{mg}$ for the immediate and extended release formulations. ${ }^{2}$ Most commonly reported side effects at therapeutic doses are headache, nausea, dry mouth, agitation, constipation and irritability. ${ }^{3}$

In therapeutic dosage, bupropion will reach its peak plasma concentration around one and a half hours for the immediate release, at 3-hours when a sustained release form is taken and at 5-hours after ingestion of the extended release form. ${ }^{2,4}$ After oral ingestion bupropion is absorbed rapidly and distributed extensively over the body (Vd of $19 \mathrm{~L} / \mathrm{kg}$ ). It mainly gets metabolized by the liver into 3 active metabolites (hydroxybupropion, threohydrobupropion, and erythrohydrobupropion). The elimination half-life of bupropion 
has been described to be approximately 21-hours, and a half-life of 20 to 37 -hours for its metabolites. ${ }^{3}$

However, studies have suggested that the peak plasma concentration and elimination half-life is prolonged when an overdose of bupropion extended release is taken compared with therapeutic ranges. ${ }^{4}$ It is also important to mention that a few cases have reported the formation of a pharmacobezoar when large doses have been ingested and this can also alter the $\mathrm{T}_{\max }$ and $\mathrm{T}_{1 / 2}{ }^{4,9}$

Since there is no known antidote for bupropion intoxication, the treatment is limited to symptom control and supportive care. ${ }^{10}$ Studies have shown that active charcoal is indicated in most cases of intoxication to partially prevent absorption. However, it is very time sensitive and should be administrated within an hour of intoxication. ${ }^{11}$ Repeated administration is recommended in case of substances that have an extended stay in the stomach. ${ }^{12,13}$ Also whole bowel irrigation might be considered in cases like these however its value has not been established yet. ${ }^{10}$ Bupropion is known to have an extensive protein binding capacity and to be highly lipophilic hence why dialysis is not indicated but lipid emulsion therapy could be considered. ${ }^{3}$ There have been some cases described in the past in which the use of lipid emulsion therapy was found to be successful. ${ }^{14,15}$ However, the evidence for the positive outcome benefits has been variable. ${ }^{16}$

Overall, the most described symptoms after intoxication are vomiting, hypertension, sinus tachycardia, QTc prolongation, cardiotoxicity, tremors, hallucination, agitation, seizures and status epilepticus. ${ }^{1,2,4,10,17-24}$ The patient in this case report experienced mainly epileptic seizures, QRS complex widening and QTc prolongation which eventually resulted in TdP and VT for which ALS and eventually VA-EMCO were indicated. When searching for other bupropion overdose cases with necessity for VA-ECMO, only 3 other cases were identified. ${ }^{5,6}$ In all cases VA-ECMO showed to be highly effective in the treatment and support of patients with severe cardiogenic shock due to bupropion poisoning. ${ }^{5,6}$ Some studies have reported that, when compared to conventional treatment, the use of VA-ECMO enhances the survival rate in patients with cardiovascular failure due to poisoning. ${ }^{25,26}$ Even though the evidence is limited and more studies are needed to confirm its benefits, we believe VA-ECMO could be an asset in the stabilization and support of patients with hemodynamic instability, due to drug intoxication and more specific bupropion intoxication.

To assure the best possible neurological outcome and overall survival for patients with the need for CPR, it is essential to have optimal chest compressions. Over the last years a lot of research has been done to find ways to optimize this in the emergency setting. In this case, ALS was guided by TEE after 20 minutes. Echocardiography has proven to be a valuable prognostic tool during cardiac resuscitation that might improve the patients' outcome. ${ }^{27}$ Studies have shown that during CPR, compressions are often performed in the incorrect location, resulting in partially obstructing the outflow track. Animal studies have also shown that there is higher coronary perfusion and improves the chance to achieve the return of spontaneous circulation (ROSC), when the area of maximal compression (AMC) is over the left ventrical. ${ }^{28}$
During TEE, the mid-oesophageal long axis view (MELAX) is considered most useful in the assessment of the AMC since it visualizes all structures of interest (left ventricle, left ventricular outflow track and ascending aorta). ${ }^{29}$ One prospective cohort study using TEE during CPR showed that in 53\% of intra-arrest cases, AMC was initially located on the left ventricle outflow track. ${ }^{28}$ During cardiac arrest TEE is not only useful to optimise the AMC but also provides continuous feedback on the quality of chest compressions, evaluates cardiac function and helps determine a cause for arrest. ${ }^{30}$ However, more studies are needed to establish the effects on the clinical outcome.

Also of interest in this case is the fact that after the administration of lidocaine, the patient evolved from VT to asystole. The ERC guidelines suggest to administer anti-arrhythmic drugs in shock- refractory, pulseless VT patients. ${ }^{31}$ It was decided to avoid amiodarone due to its QTc prolonging effect and use lidocaine instead. Lidocaine is a Vaughan-Williams class Ib antiarrhythmic drug, that is known to shorten the QTc interval and has been used successfully in the treatment of ventricular tachyarrhythmias. ${ }^{32}$ However, there have been a hand full of cases reporting asystole after lidocaine administration due to the depressing effect lidocaine has on the sinoatrial and atrioventricular node. ${ }^{78}$ In vivo studies showed that bupropion antagonizes sodium channels in cardiac tissue ${ }^{33}$ therefore we believe that lidocaine should be avoided for the treatment of VT in bupropion intoxication cases. However, further in-depth research is needed to establish the anti-arrhythmic drug that would be considered first choice in cases of recurring VT and TdP with prolonged QTc interval.

\section{CONCLUSION}

Severe extended release bupropion intoxication usually results in severe neurological symptoms and cardiotoxicity. Our patient experienced seizures, bradycardia and eventually QRS-complex widening and QTc prolongation resulting in recurring ventricular tachycardia, torsades de pointes and asystole. A multi target approach of active charcoal administration, medical management for symptom control, optimisation of chest compressions during resuscitation and placement of VA-ECMO resulted in successful treatment of this intoxication and has led to a full patient recovery despite prolonged cardiac arrest (Table 1).

Table I. Suggested Therapy Following Severe Bupropion Intoxication

Activated charcoal (when unsuccessful consider pharmacobezoar formation)

Whole bowl irrigation

Lipid emulsion therapy

Sodium bicarbonate for bupropion induced bradycardia

VA-ECMO in severe hemodynamically unstable patients

\section{CONSENT}

The patient presented in this case was contacted and informed. Oral consent from the patient was given.

\section{CONFLICTS OF INTEREST}

The authors declare that they have no conflicts of interest. 


\section{REFERENCES}

1. Zhu Y, Kolawole T, Jimenez XF. Atypical findings in massive bupropion overdose: A case report and discussion of psychopharmacologic issues. J Psychiatr Pract. 2016; 22(5): 405-409. doi: 10.1097 / PRA.0000000000000179

2. Jefferson JW, Pradko JF, Muir KT. Bupropion for major depressive disorder: Pharmacokinetic and formulation considerations. 2005; 27:1685-95. doi: 10.1016/j.clinthera.2005.11.011

3. Costa R, Oliveira NG, Dinis-Oliveira RJ. Drug metabolism reviews pharmacokinetic and pharmacodynamic of bupropion: integrative overview of relevant clinical and forensic aspects Pharmacokinetic and pharmacodynamic of bupropion: Integrative overview of relevant clinical and forensic aspects. Drug Metab Rev. 2019; 51(3): 293-313. doi: 10.1080/03602532.2019.1620763

4. Donnelly K, Walkowiak HB, Donnelly C, Jenkinson E, Rizkalla J, Langford N. Bupropion toxicokinetic: A case report. Clin Toxicol. 2010; 48(4): 385-387. doi: 10.3109/15563651003623289

5. Heise CW, Skolnik AB, Raschke RA, Owen-Reece H, Graeme $\mathrm{KA}$. Two cases of refractory cardiogenic shock secondary to bupropion successfully treated with veno-arterial extracorporeal membrane oxygenation. J Med Toxicol. 2016; 12(3): 301-304. doi: 10.1007/s13181-016-0539-7

6. Shenoi AN, Gertz SJ, Mikkilineni S, Kalyanaraman M. Refractory hypotension from massive bupropion overdose successfully treated with extracorporeal membrane oxygenation. Pediatr Emerg Care. 2011; 27(1): 43-45. doi: 10.1097/PEC.0b013e3182045f76

7. Applebaum D, Halperin E. Asystole following a conventional therapeutic dose of lidocaine. Am J Emerg Med. 1986; 4(2): 143145. doi: 10.1016/0735-6757(86)90160-9

8. Manyari-Ortega DE, Brennan FJ. Lidocaine-induced cardiac asystole. Chest. 1978; 74(2): 227-229. doi: 10.1378/chest.74.2.227

9. Schmit G, De Boosere E, Vanhaebost J, Capron A. Bupropion overdose resulted in a pharmacobezoar in a fatal bupropion (Wellbutrin $^{\circledR}$ ) sustained-release overdose: Postmortem distribution of bupropion and its major metabolites. J Forensic Sci. 2017; 62(6): 1674-1676. doi: 10.1111/1556-4029.13497

10. Jepsen F, Matthews J. Sustained release bupropion overdose: an important cause of prolonged symptoms after an overdose. Emerg Med J. 2003; 20: 560-561. doi: 10.1136/emj.20.6.560

11. Stall N, Godwin J, Juurlink D. Five things to know about $\square$ : Bupropion abuse and overdose. CMAJ. 2014; 186(13): 1015. doi: 10.1503/cmaj.131534

12. Greene S, Harris C, Singer J. Gastrointestinal decontamination of the poisoned patient. Pediatr Emerg Care. 2008; 24(3): 176-186. doi: 10.1097/PEC.0b013e318166a092
13. Zellner T, Prasa D, Färber E, Hoffmann-Walbeck P, Genser D, Eyer F. The use of activated charcoal to treat intoxications. Dtsch Aratebl Int. 2019; 116(18): 311-317. doi: 10.3238/arztebl.2019.0311

14. Bornstein K, Montrief T, Anwar Parris M. Successful management of adolescent bupropion overdose with intravenous lipid emulsion therapy. J Pediatr Intensive Care. 2019; 8(4): 242-246. doi: $10.1055 / \mathrm{s}-0039-1693483$

15. Herrman NWC, Kalisieski MJ, Fung C. Bupropion overdose complicated by cardiogenic shock requiring vasopressor support and lipid emulsion therapy. J Emerg Med. 2020; 58(2): e47-e50. doi: 10.1016/j.jemermed.2019.11.029

16. Chhabra N, DesLauriers C, Wahl M, Bryant SM. Management of severe bupropion poisoning with intravenous lipid emulsion. Clin Toxicol. 2018; 56(1): 51-54. doi: 10.1080/15563650.2017.1337909

17. Morazin F, Lumbroso A, Harry P, Blaise M, Turcant A, Montravers $\mathrm{P}$, et al. Cardiogenic shock and status epilepticus after massive bupropion overdose. Clin Toxicol. 2007; 45(7): 794-797. doi: $10.1080 / 15563650701665076$

18. Stewart E, Grewal K, Hudson H, Thompson M, Godwin J. Clinical characteristics and outcomes associated with bupropion overdose: A Canadian perspective. Clin Toxicol. 2019; 58(8): 837842. doi: 10.1080/15563650.2019.1699658

19. Spiller HA, Ramoska EA, Krenzelok EP, Sheen SR, Borys DJ, Villalobos D, et al. Bupropion overdose: A 3-year multi-center retrospective analysis. Am J Emerg Med. 1994; 12(1): 43-45. doi: 10.1016/0735-6757(94)90195-3

20. Franco V. Wide complex tachycardia after bupropion overdose. Am J Emerg Med. 2012; 32(3): 1540. e3-5. doi: 10.1016/j. ajem.2015.07.063

21. Paris PA, Saucier JR. ECG conduction delays associated with massive bupropion overdose. J Toxicol Clin Toxicol. 1998; 36(6): 595598. doi: 10.3109/15563659809028055

22. Isbister GK, Balit CR. Bupropion overdose: QTc prolongation and its clinical significance. Ann Pharmacother. 2003; 37(7-8): 9991002. doi: 10.1345/aph.1C481

23. Balit CR, Lynch CN, Isbister GK. Bupropion poisoning: A case series. Med J Aust. 2003; 178(2): 61-63. doi: 10.5694/j.13265377.2003.tb05064.x

24. Starr P, Klein-Schwartz W, Spiller H, Kern P, Ekleberry SE, Kunkel S. Original contribution incidence and onset of delayed seizures after overdoses of extended-release bupropion. Am J Emerg Med. 2009; 27: 911-915. doi: 10.1016/j.ajem.2008.07.004

25. Daubin C, Lehoux P, Ivascau C, Tasle M, Bousta M, Lepage O, et al. Extracorporeal life support in severe drug intoxication: A retrospective cohort study of seventeen cases. Crit Care. 2009; 13(4): 
R138. doi: 10.1186/cc8017

26. Masson R, Colas V, Parienti J-J, Lehoux P, Massetti M, Charbonneau $\mathrm{P}$, et al. A comparison of survival with and without extracorporeal life support treatment for severe poisoning due to drug intoxication. Resuscitation. 2012; 83(11): 1413-1417. doi: 10.1016/j. resuscitation.2012.03.028

27. Kedan I, Ciozda W, Palatinus JA, Palatinus HN, Kimchi A. Prognostic value of point-of-care ultrasound during cardiac arrest: A systematic review. Cardiovasc Ultrasound. 2020; 18(1): 1. doi: 10.1186/s12947-020-0185-8

28. Teran F, Dean AJ, Centeno C, Panebianco NL, Zeidan AJ, Chan W, et al. Evaluation of out-of-hospital cardiac arrest using transesophageal echocardiography in the emergency department. Resuscitation. 2019; 137: 140-147. doi: 10.1016/j.resuscitation.2019.02.013

29. Mayo PH, Narasimhan M, Koenig S. Critical care transesophageal echocardiography. Chest. 2015; 148(5): 1323-1332. doi:

\section{$10.1378 /$ chest. $15-0260$}

30. Labovitz AJ, Noble VE, Bierig M, Goldstein SA, Jones R, Kort $\mathrm{S}$, et al. Focused cardiac ultrasound in the emergent setting: A consensus statement of the American society of Echocardiography and American College of Emergency Physicians. I Am Soc Echocardiogr. 2010; 23(12): 1225-1230. doi: 10.1016/j.echo.2010.10.005

31. Monsieurs KG, Nolan JP, Bossaert LL, Greif R, Maconochie IK, Nikolaou NI, et al. European resuscitation council guidelines for resuscitation 2015: Section 1. Executive summary. Resuscitation. 2015; 95: 1-80. doi: 10.1016/j.resuscitation.2015.07.038

32. Tisdale JE, Chung MK, Campbell KB, Hammadah M, Joglar JA, Leclerc J, et al. Drug-induced arrhythmias: A scientific statement from the American Heart Association. Circulation. 2020; 142: e214-e233. doi: 10.1161/CIR.0000000000000905

33. Curry SC, Kashani JS, LoVecchio F, Holubek W. Intraventricular conduction delay after bupropion overdose. The Journal of Emergency Medicine. 2005; 29: 299-305. doi: 10.1016/j.jemermed.2005.01.027 